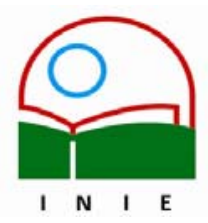

Universidad de Costa Rica

Facultad de Educación

Instituto de Investigación en Educación

ACTUALIDADES INVESTIGATIVAS EN EDUCACION

\title{
TRES MIRADAS AL MUNDO DE LOS MEDIOS DIGITALES Y LA COMUNICACIÓN
}

\author{
Oscar Coronado Jurado ${ }^{1}$ \\ A la memoria de \\ mi padre Álvaro Coronado Robles (1928-1995) \\ Director del Centro de Computación \\ Electrónica de la Caja Costarricense del Seguro Social de 1948 a 1978. \\ Precursor anónimo de la Informática en Costa Rica.
}

\begin{abstract}
Resumen: Este trabajo tiene como propósito abordar tres temas principales del binomio Medios Digitales y Educación: en primer lugar, los Mapas Conceptuales, luego la subjetividad y el aprendizaje en la interacción con el computador y, por último, Internet y su impacto en la educación y en la organización del trabajo. Usando como metodología la investigación bibliográfica, retoma el pensamiento de Novak y de Alberto Cañas, del cual se deriva que los Mapas Conceptuales, son una poderosa herramienta e instrumento, para la modelación rápida y precisa de simples y complejas relaciones causales-jerárquicas y cognitivas. Se aborda el estudio de Sherry Turkle con su libro "La vida en la pantalla. La construcción de la Identidad en la era de Internet", en el que concluye que la interacción con el computador, después de examinar los llamados M.U.D. (Dominios de Múltiples Usuarios), los estilos de programación, las estéticas y culturas asociadas; en un lapso del desarrollo de la informática, en que el autor reseña -en ocasiones- sus propias experiencias tiene implicaciones fundamentales en la calidad del aprendizaje, la subjetividad y la conciencia colectiva y en comunidad, con importantes hallazgos culturales y psicológicos.

Por último se caracteriza a Internet, red de redes, y su profundo impacto en todos los órdenes, especialmente en la forma de aprender y en la estructura reticular de las empresas, a partir del pensamiento de Manuel Castells en su libro "La Galaxia Internet". Pero lo esencial, como un factor que determina y determinará, la inclusión o exclusión de las naciones, regiones o pueblos, a un desarrollo en que quepamos todos.
\end{abstract}

\section{Palabras clave: MAPAS CONCEPTUALES/ DOMINIOS DE MÚLTIPLES USUARIOS (M.U.D.)/ INTERNET/}

\begin{abstract}
The purpose of this paper is to discuss three of the main themes of the Digital Media and Education binomial: in the first place, concept maps, followed by subjectivity and learning in the interaction with the computer, and finally, Internet and its impact on education and the organization of work. Using bibliographical research as the methodology, Novak and Alberto Cañas thoughts were considered and from this, it has been found that concept maps are a powerful instrument and tool for the rapid and precise modelling of simple and complex causal, hierarchical, and cognitive relationships. Sherry Turkle's research in the book Life on the screen: the construction of identity in the Internet era, was analysed, and it is concluded that the interaction with the computer has fundamental implications, after examining the so called Multi-user domains (M.U.D.), the styles of programming and the associated aesthetics and cultures; in the lapse of the development of computer science, in which the author notes -on certain occasions- his own experiences. It has implications on the quality of learning, subjectivity and collective and community awareness, with important cultural and psychological findings. Finally, Internet, web of webs, is characterized, and so is its profound impact in all orders, especially in the way of learning and the reticular structure of businesses, considering the research of Manuel Castells in his book The Internet Galaxy. Most importantly, as a factor that determines and will determine, the inclusion or exclusion of nations, regions or people, in a development in which there shall be room for all.
\end{abstract}

Key words: CONCEPT MAPS/ MULTI-USER DOMAINS (M.U.D.)/ INTERNET/

\footnotetext{
${ }_{1}^{1}$ Director del Departamento de Producción de la Escuela de Ingeniería Industrial, Universidad de Costa Rica.
}

Correo electrónico: oscorona@ice.co.cr

Artículo recibido: 12 de julio, 2005

Aprobado: 13 de diciembre, 2005 


\section{Introducción}

En este artículo se hace un planteamiento de tres temas, aparentemente inconexos de los medios digitales y la educación. Se realiza un breve análisis de los Mapas Conceptuales como instrumento - herramienta para el aprendizaje y la modelación en el computador, los que se basan en un enfoque constructivista de la educación. Luego se profundiza, mediante el estudio de una investigación sobre la subjetividad, los estilos de programación y los aspectos psicológicos de la computación y sus usuarios, con un trasfondo educativo innegable, en virtud de los temas y su tratamiento.

Corresponde la investigación analizada a otra época del desarrollo de la computación, pero ello no le hace perder vigencia y actualidad. Esta investigación es multidimensional en el ámbito de la cultura del computador.

Por último se hace un análisis de Internet, como poderoso instrumento que puede determinar la inclusión o exclusión, en la inserción de los países subdesarrollados, a la sociedad de la información y el conocimiento.

Es bien sabido, el impacto de Internet en la educación, sobre todo cuando su aprendizaje se inicia desde la niñez. Es así como estos tres temas constituyen tres ventanas, para dar una mirada sobre el computador y la educación.

En este artículo se mencionan lugares como el Valle el Silicón, centro mundial de la industria de la computación, situado en el condado de Santa Clara, al sur de San Francisco California. Los estudios de la cultura computacional se desarrollaron en el Instituto Tecnológico de Massachussets y la Universidad de Harvard. Pero precisamente y sobre el Valle del Silicón, veremos que las empresas organizadas en forma de red y como producto de Internet, tienden a descentralizarse y desconcentrarse, por lo que el Valle del Silicón, tiende a perder importancia relativa, Esto lo abordaremos en el apartado 3.

\section{Mapas conceptuales: herramienta-instrumento educativo-investigativo- científico-técnico de vanguardia}

Nos hallamos ahora en el inicio de un período en el que casi todo el mundo podrá acceder -gratis- a casi todas las cosas conocidas. El problema consiste en cómo emplear dicho potencial para mejorar la vida de los seres humanos de todo el mundo (Novak, 1998, p. 282). 


\subsection{Propósito}

La cita de Novak, el introductor de esta poderosa herramienta, es crucial en nuestro ensayo. La brecha digital, simboliza en el primer lustro del tercer milenio, la distancia que separa, abismalmente-, los Estados-Nación metropolitanos de los periféricos, los continentes, de los países centrales, de los subdesarrollados, eufemísticamente en "vía de desarrollo", desarrollo que sabemos casi imposible desde la división internacional del trabajo. Aún cuando la economía, basada en uso intensivo de Internet, podría en la nueva aldea global brindar una esperanza, tal y como apuntamos en el apartado 3.

\subsection{Herramientas o Instrumentos}

Tenemos un problema de naturaleza epistemológica en virtud de que debemos desligar la raíz inglesa de las palabras-herramienta (tool) e instrumento (instrumental). A continuación abordaré este asunto.

\section{3 ¿Qué son los Mapas Conceptuales (MC)?}

EI MC plasma gráficamente un conjunto de conceptos y sus vinculaciones, sobre la base de un campo(s) dado(s) de conocimiento(s), concebida de forma tal que se evidencian y visibilizan con gran claridad, las diversas gradación de fuerza y causalidad de esas vinculaciones. Ello por supuesto en diferentes niveles de complejidad ya que si el uso es educativo, a nivel materno infantil, se podrá resaltar un solo nivel de vinculación. Y así "incressendo", el nivel de complejidad de las vinculaciones con los enlaces (arcos) y nodos que se rotulan-, y ambos, pueden y de hecho asumen formas iconográficas (matemáticasgeométricas-imágenes de toda índole-criptográficas-ideográficas, etc.) en atención al usuario y sus requerimientos.

Pero, lo más importante, es que el aprendiz, construye desde la más tierna edad, con un software muy amigable, sus propias creaciones, desarrollando facultades cognitivas, de naturaleza espacial de perspectiva, conceptual, causal, multireferencial, de gran riqueza. Todo esto, abre enormes perspectivas educativas.

Para evitar confusiones, es importante distinguir entre el instrumento-herramienta que son los Mapas Conceptuales del software más utilizado para construirlos: el C Map Tools. La conclusión, es que herramienta, es cuando el modelo, software, diagrama o método, sirve 
para realizar un constructo, como un diagrama de flujo de datos, un diagrama lógico, un diagrama físico, una distribución en planta, un multicolumnar de flujo de macroproceso, etc.

El instrumento es "inteligente", como un paquete de simulación, de análisis de datos, o de ACP (Análisis de Componentes Principales). Los MC (Mapas Conceptuales), se pueden utilizar para enseñanza e investigación de alto nivel, luego tienen esa connotación. Basta leer detenidamente el artículo de Alberto Cañas del que extraemos la siguiente cita:

Las herramientas son sumamente flexibles, y entre sus usuarios se encuentra desde niños de educación primaria en Latinoamérica, hasta científicos sobre el lugar más apropiado para el descenso de naves espaciales en Marte. Los modelos creados sirven como organizadores que pueden navegar en busca de información, basándose en el conocimiento de experto como guía en la navegación. Los estudiante, además de usarlo para mostrar gráficamente su conocimiento sobre un tema específico, colaboran electrónicamente entre sí en la construcción de sus mapas, video, texto, etc., los ligan aquellos estudiantes de su escuela u otras escuelas, o a los mapas de expertos, y automáticamente publicándolos, permitiendo la navegación de otros estudiantes. Científicos usan las herramientas para representar y publicar modelos de sus investigaciones, promoviendo la colaboración entre ellos. La creación de módulos sobre diferentes temas por parte de profesores está siendo utilizada como técnica a distancia como dentro del aula. (Cañas, 2005, p. 1)

Los mapas conceptuales utilizan como base epistemológica, la teoría de grafos, los nodos y los enlaces (arcos en investigación operacional), se utilizan en dos vías fundamentales:

a. Un canal de descripción y comunicación.

b. La base cognoscitiva, la teoría de la asimilación, una teoría de aprendizaje, constructivista, que tiende a afirmar y apuntalar lo que el estudiante ya ha aprendido.

\subsection{Epílogo}

Los Mapas Conceptuales, son una herramienta-instrumento, de naturaleza prodigiosa para la educación, la investigación, la gestión empresarial, y otras muchas aplicaciones.

Se puede decir, que constituyen una invención, de la dimensión del transistor, por su trascendencia y potencial en los campos mencionados. 
El inventor Joseph D. Novak, en el libro de la referencia, hace importantes reflexiones, sobre una serie de tópicos relacionados con el poder, con la exclusión y con las oportunidades.

Novak, como los grandes hombres, sabe lo crucial de su invención y comprende que la ciencia y la técnica, pueden usarse para la guerra, el exterminio y el genocidio, o para la enseñanza, el combate contra la pobreza, la enfermedad o los desastres. Para abrir puertas para el desarrollo, o para cerrarlas. De ahí la importancia de luchar en la práctica por abrir la brecha digital.

El artículo de Resnick ${ }^{2}$ (1998, Thinking like a tree) revela, una interesantísima aplicación de caminatas en el bosque lluvioso de Costa Rica, con tres estrategias:

- Examen al Azar (buscando rutas en todas direcciones).

- Evaluación (determinando cada ruta terminando en el mapa).

- Elección (eligiendo cada dirección para moverse, basados en la información sobre las rutas).

\section{De los MUD a la complejidad de la mente humana, ¿podrán las máquinas llegar a sentir y pensar? \\ En su libro "La vida en la Pantalla", Sherry Turkle $^{3}$ (1997) nos muestra en forma polidimensional, un mundo de tensión entre lo real y lo virtual.}

El trabajo de Turkle, se basa en los MUD, Dominios para Múltiples Usuarios, o Mazmorras para Múltiples Usuarios, el juego de rol, que provocó sensacionales efectos en las facultades, a fines de las décadas de los setentas y principios de los ochenta, basados en la

\footnotetext{
${ }^{2}$ Mitchel Resnick pertenece al equipo de investigación del MIT Media Laboratory

${ }^{3}$ La Dra. Turkle, es una privilegiada observadora e investigadora, porque vivió el desarrollo informático desde finales de los sesenta.

Con una formación de grado y Doctorado en Sociología, Antropología y Psicología Clínica de la Personalidad, además Terapeuta Licenciada y graduada por el Instituto Psicoanalítico de Boston. Sus estudios doctorales los llevó a cabo en Francia y vivió la Revolución de 1968.

Durante casi 20 años, al momento de escribir su obra 1994, había enseñado Ciencias Sociales en el MIT, y practicado la psicoterapia durante 15 años.

Su contacto con la computación más formal, comienza a finales de los setenta y desde 1987 a 1989 , después de participar en muchas investigaciones acerca del estado de la apropiación de las ideas que rodean los artefactos técnicos, el proyecto Athena, una investigación etnográfica entre otras muchas, comienza sus investigaciones interculturales haciendo entre muchas una investigación de campo en la antigua Unión Soviética.
} 
cultura de la simulación, en diferentes ambientes de interconectividad y en la naciente Internet.

En la historia de la construcción de la identidad en la cultura de la simulación, las experiencias sobre Internet figuran de forma prominente, aunque estas experiencias sólo se puedan comprender como parte de un contexto cultural más amplio. Este contexto es la historia de la erosión de las fronteras entre lo real y lo virtual, lo animado y lo inanimado. (Turkle, 1997, p. 22)

Se trata de un juego interactivo asentado en frases de texto, cuyo diseño está basado para representar un rico mundo virtual, y muchos miles de jugadores, dedican hasta ochenta horas por semana participando en diversas aventuras cósmicas y batallas.

Son juegos de roles, que a través de instrucciones crean personajes que construyen sus propias moradas, cambian de género, asisten a ritos, cumplen reglas, se enamoran, flirtean y hasta se casan. En este juego, el yo se construye, las reglas de socialización se constituyen en comunidad.

En otro juego, unos mil jugadores crean cada uno su ego, o varios "egos", definiendo su género y otras características físicas y psicológicas. No se requiere que los "egos" sean humanos y puede haber más de dos géneros.

Utilizando un lenguaje informático simple, construyen su "casa" virtual, en el dominio del juego, en la que se sitúa el escenario y el ciberjugador define normas.

Los MUD nos sitúan en espacios virtuales donde es factible navegar, conversar, construir y ¡destruir! Mientras llevan a cabo tal experiencia, algunos ciber-MUD, experimentan vidas múltiples, en las que la vida real (VR) es solo una más, juna ventana más!

El desarrollo de ventanas (windows) por Apple Computers, después "tomada prestada" por Microsoft, fue una crucial innovación técnica, motivada por la intención de que la gente trabajara en forma más productiva, teniendo varias aplicaciones simultáneamente, y "saltara", de una aplicación a otra, con una concepción "multitasking", multitarea. 
Sin embargo en la práctica diaria de muchos usuarios de ordenador, las ventanas se han convertido en una metáfora poderosa para pensar en el yo como un sistema múltiple, distribuido (Turkle, 1997, p. 21).

Esto tiene implicaciones fundamentales en el psicoanálisis, fundamentalmente en el pensamiento de Jacques Lacan $^{4}$, a quien no sigo, pero sí se le debe reconocer su aporte, en la concepción del inconciente no como una unidad monolítica, sino como una serie descentralizada de entidades, que constituyen una entidad, sin que ello implique necesariamente el padecimiento del Síndrome de Personalidades Múltiples. Esto, a riesgo de una sobresimplificación, y de una distorsión del pensamiento lacaniano, sobre el cual, además, he leído algunas pocas obras.

"El yo está constituido por el lenguaje, a través de lenguaje el congreso sexual, es el intercambio de significantes y cada uno de nosotros, es una multiplicidad de fragmentos y conexiones deseantes" (Turkle, 1997, p. 22).

Son las ideas de Lacan, Foucault, Deleuze y Guattari, que la autora, los encuentra, o más bien les reencuentra, en sus investigaciones, de los mundos mediados por el computador, el yo es múltiple, en flujo e interacción con conectividad en la máquina.

El yo está basado y trasfigurado por el lenguaje (Freud), el congreso sexual es un trasiego de significantes; y la comprensión deriva del navegar en Internet, y la transposición de juegos, constructos y exploraciones en y dentro de la máquina (el bricolaje), más que del análisis.

El Pos-Modernismo, visto a través de los MUD, se concibe como un espacio descentrado, fluido no lineal, contrasta con la visión del mundo dominante desde la llustración. A través de la computadora, escribe la autora ${ }^{5}$, la gente llega a cierta comprensión sobre el significado del pos-modernismo.

\footnotetext{
${ }^{4}$ A Lacan, debemos reconocerle, además su condición de líder, junto con Foucault y Sartre y otros, de la Revolución de París 1968, que se reprodujo en todo el mundo occidental

${ }^{5}$ La autora hace importantes reflexiones, sobre la educación, y como los aprendientes caracterizan la máquina, cómo les ven, como ser vivo o no, y qué razones dan para ello. Cita a Piaget, y como reniega de sus propios hallazgos, para la autora, realmente válidos. La pregunta crucial ¿un artefacto puede estar vivo?, la deja sin responder, dando lugar a la reflexión del lector.
} 


\subsection{Dos estéticas en tensión}

En un cuento de Dos Estéticas nos sitúa la autora en los albores del inicio del computador personal, cuando el aficionado-adicto, el hacker (andar al borde del abismo) podía programar su propio aparato, desarmarlo, conocer sus componentes, hasta la mínima expresión y reconfigurarlo.

(...) Una característica de la computación que ha llevado a los filósofos de la mente a ver la interacción hardware-software como una evocación de la relación irreducible del cerebro y la mente (...) (Turkle, 1997, p. 45).

\begin{tabular}{|c|c|}
\hline CP / M APPLE COMPUTER & IBM - AT - WINDOWS-85 \\
& Y CLONES \\
\hline No era explorable sino para & Mantiene D $\phi S$ como \\
usuarios especializados & base transparente \\
que pudieran & así se puede manipular \\
"entrar" a RES-EDIT & Windows \\
& que a su vez está escrito en C \\
\hline
\end{tabular}

Se podía incursionar como hacker en las IBM y sus clones, no así en las MAC y la Pos Moderna de las MAC, se funden.

La opacidad estimulaba las personas a relacionarse con la tecnología, como se relacionaba con las personas: es decir es el ámbito de la superficialidad.

Escribiendo sobre "Joel" uno de sus entrevistados, señala:

(...) Pero cree que si aceptamos la opacidad de la sociedad podemos navegar sobre sus contornos de manera más efectiva. Señala que cuando el teórico posmoderno Jean Baudrillard escribió sobre la seducción de la tecnología, habló sobre los placeres de la opacidad (...). (Turkle, 1997, p. 58)

Por opacidad social, se entiende que no se profundiza, se ven las consecuencias, no las causas. Es una forma de abordar la realidad, desde la despreocupación y la apatía. Semejante a la que experimenta un usuario de una máquina, a la que es imposible sin ser un 
programador avezado, entender qué ocurre por dentro de la máquina. Baudrillar exalta el placer de relacionarse con la tecnología, sin profundizar en su funcionamiento.

Es importante resaltar cómo la autora, sitúa y hace corresponder, el desarrollo de la computación personal, con concepciones estéticas, los de la profundidad y la de opacidad, y cómo se inscriben en la historia de la cultura contemporánea y repetimos posteriormente el desarrollo tecnológico hace que ambas estéticas se reencuentren. Continúa la autora, identificando tres culturas informáticas a inicios de los 80 , con una riquísima retrospectiva de naturaleza historiográfica: las culturas ARPANET (la red precursora de Internet), la cultura del famoso sistema operativo UNIX, la cultura PC, inicial, con micros, con Basic escrito en ensamblador ${ }^{6}$.

\subsection{Dos Escuelas de Programación- Dos Concepciones Científicas en Tensión}

"El triunfo de bricolaje" es una progresión de la historia de la programación a base de diagramas de flujo y grafos de la técnica de programación estructurada, matemáticamente precisa, característica del aprendizaje de FORTRAN II y FORTRAN IV, con el uso privilegiado de aplicaciones de métodos numéricos, por ejemplo, para aproximaciones a la solución de ecuaciones múltiples, o a problemas de optimización como alternativas al uso del cálculo diferencial e integral, hacia la programación "blanda".

Esta última llamada programación del bricolaje, o de la unión libre de "pedacitos de papel", según lo autora, está más adecuada al funcionamiento integral del cerebro humano, ya que utiliza no solo las funciones analíticas, sino las intuitivas, poéticas, artísticas, y otras dimensiones cognitivas y espirituales. Incluso a la programación blanda, le da una connotación femenina.

La autora ilustra con ejemplos de sus investigaciones y citas de numerosos investigadores, sus hallazgos en el bricolaje. Es importante apuntar sus alusiones a las concepciones científicas subyacentes en ambas culturas de programación y en sus estéticas asociadas.

\footnotetext{
${ }^{6}$ En primer lugar, RES-EDIT, era el sistema operativo de Macintosh (Apple); D $\phi S$ el sistema operativo inicial de Microsoft, desde el cual se podía manipular Windows, escrito en lenguaje C; DEC son las siglas de Digital Electronic Corporation; BASIC es un lenguaje característico de las primeras microcomputadoras; UNIX es un sistema operativo, del que hubo múltiples versiones. 
Una la estructura, correspondía a una ciencia cartesiana, lineal y canónica, otra, a una ciencia posmoderna, humanista y no lineal, no determinista y holista.

(...) La estética del diseño del nuevo software, dice de forma efectiva que los usuarios del ordenador no deben trabajar con sintaxis, tienen que ser capaces de jugar con la forma, el color y el sonido (...). (Turkle, 1997, p. 78)

Después plantea que: “(...) En la cultura emergente de la simulación, el ordenador es todavía una herramienta que se parece menos a un martillo y más a un clavicémbalo (..)" (Turkle, 1997, p. 79).

Una metáfora afortunada, en el mismo sentido de asociar el arte, lo lúdico, la sensibilidad, a la cultura de la simulación, y al uso de todos los recursos cognitivos, de cara a la pantalla del computador.

Termina la reflexión al exponer la tensión entre lo real y lo virtual, y las connotaciones éticas y morales de los juegos en el mundo virtual, y cómo fácilmente las conductas en ese ámbito, o al menos las bases éticas se extrapolan o pueden extrapolarse al mundo real, y además cómo ambas instancias tienden a confundirse con el imaginario subjetivo y colectivo.

En suma, la programación estructurada o canónica, es producto de una cultura matemática, que inhibe otras posibilidades del programador. La programación del bricolaje o blanda asocia lo artístico y una metodología que convoca a otros recursos cognitivos del programador. Su veta artística, intuitiva y lúdica.

\subsection{Los Mud - Una reflexión sobre la psicología, el Yo, las comunidades y el papel del terapeuta}

Los dominios de múltiples usuarios son la realidad como hemos visto, el tema central de la investigación de la autora que nos ocupa. En la introducción hemos hecho una descripción somera de estos virtuales y de algunas tensiones, conflictos y hallazgos contenidos en el texto. Castells también se refiere a los MUD y al trabajo de Turkle, autor al que nos referiremos en el siguiente capítulo.

Construir espacios en los MUD, es una instancia que oscila entre la informática (escribir textos como instrucciones) y escribir literatura de ficción. Se trata de acceder a la Realidad Volumen 5, Número 2, Año 2005, ISSN 1409-4703 
Virtual, a través de la interacción con el computador, utilizando un software especial, que en versiones diversas, al usuario le permite construir sus propias habitaciones, sus propios personajes, con posibilidad de cambiar de género(s).

La autora distingue, el término "Personae", utilizado en los MUD, palabra latina que en español significa:

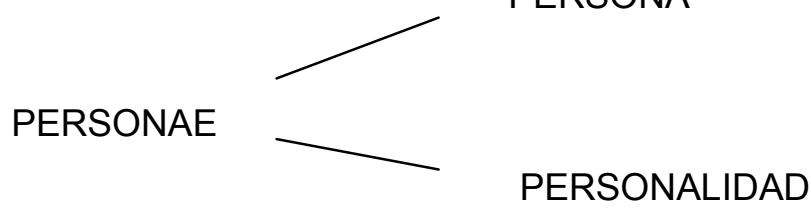

Y plantea: "La derivación implica que identificamos a alguien por un rostro público distinto de una esencia o esencias más profundas" (Turkle, 1997, p. 231).

Los MUD están organizados alrededor del espacio físico. Es posible ver iglesias medievales, o un palacio de connotaciones laberínticas. Los personajes virtuales charlan unos con otros, utilizan gestos, manifiestan emociones, ganan y pierden dinero. Ascienden en la jerarquía social o descienden de ella. Pueden incluso morir.

Los MUD, ofrecen mundos para una relación social, desde el anonimato, en el que se puede jugar un rol, tan próximo o tan lejano, al personaje real, según el jugador elija. De ahí, que tienden a provocar adicción, por ejemplo personas que juegan 6 horas al día y hasta $12 \mathrm{si}$ usan computadora en su trabajo, donde incluyen una ventana, entre las ventanas propias de su empleo.

El espacio en que se desarrolla el jugador del MUD, hace que se desenvuelvan las escenas y eclosione un singular dramatismo, que hace surgir la paradoja de que, es a la vez similar pero diferente al ver televisión.

La situación de estar en ese espacio virtual, se puede convertir en una instancia que podría permitir al jugador descubrir, escudriñar quiénes y quién desea ser. Implican diferencia, multiplicidad y fragmentación, ya que el participante puede construir múltiples personajes, y como había apuntado en la Introducción, el yo no solo se ha descentralizado, arrastrando al 
inconsciente, sino que se multiplica, tantas veces, como la voluntad de ese participante le dicte.

Los juegos tradicionales de cambio de rol, que tienen lugar en la vida real, son particularmente interesantes desde el punto de vista psicológico, y por supuesto asumen dimensiones dramáticas. Ello ha formado toda una escuela en el psicoanálisis, el Psicodrama ${ }^{7}$.

Los MUD, a criterio de Turkle, son más interesantes y evocativos, ya que: "En los juegos de rol cara a cara, entramos y salimos de los personajes. Los MUD, por el contrario, ofrecen un personaje o personajes que se pueden convertir en identidades paralelas" (Turkle, 1997, p. 236).

Pero el asunto es siempre bordear la frágil frontera entre lo virtual y lo real, que puede hacer avanzar al personaje en su proyecto de vida real, pero también hacerlo retroceder atrozmente.

La historia de Pigmalión perdura porque habla de una fantasía poderosa: no estamos limitados por nuestras propias historias, podemos volver a crearnos (Turkle, 1997, p.244).

La pregunta si los MUD, ¿se constituyen en psicoterapia o adicción?, la resuelve la autora, planteando que si bien a algunos de los usuarios de los MUD les sirve para liberarse y expresarse en forma positiva; los programas diseñados para hacer el rol del analista, ni los MUD, son sucedáneos de la psicoterapia, y en algunos casos el uso de esos espacios se vuelve una adicción indeseable y escapista, que profundiza conflictos y psicopatologías.

Algunos jugadores tienen experiencias escapistas y depresivas en sus incursiones en el MUD, otros incluso aprovechan su experiencia para un autodescubrimiento, y dejan una carta emocional negativa atrás y cambian positivamente su vida.

${ }^{7}$ Cuyo padre es E. Parini, y su principal discípula y divulgadora es Ursula Hauser, con quien tuve la inmensa suerte, de tenerla como analista durante varios años, y hoy es mi amiga, ya no reside sino unos pocos meses en Costa Rica. 
Los cambios de rol sexual, ofrecen en la investigación de la autora, toda una gama de amplio espectro, con experiencias positivas y negativas en los extremos, que por la complejidad del tema no lo abordaré.

* El efecto Pigmalión es típico de los MUD, algunos "salen" de sus cuartitos modestos de facultad, donde son insignificantes y tímidos, para convertirse en poderosos y vivos seductores playboys en los MUD.

* Otros jugadores pueden ser propensos a matar y violar, y así entramos en el terreno ético y moral.

Solo poquísimas veces los jóvenes intentan y logran resolver con el uso de los MUD's, conflictos con pares del mundo real.

En cuanto al uso del MUD, como sucedáneo para las relaciones de los adolescentes, la postura es que en esa etapa, las relaciones, se basan en una comprensión mutua, que deriva en un cierto compromiso normado y limitado. El espacio virtual, es poco o nada propicio para esas relaciones, ya que los MUD, pueden vertebrar una intimidad fácil e irreal.

Cuando todo consta en el registro y nada está en el registro, nos preguntamos hasta qué punto las relaciones no son fruto de la imaginación de las personas... Los MUD alientan la proyección y el desarrollo de transferencias por las mismas razones que lo hace una situación clásica del análisis freudiano... En los MUD, la falta de información sobre la persona real con la que uno habla, el silencio con el que uno teclea, la ausencia de pistas virtuales, todo ello alienta la proyección. Esta situación conduce a preferencias y antipatías exageradas a la idealización o demonización. Así la persona se siente defraudada cuando conoce en persona a sus amantes virtuales. (Turkle, 1997, p. 262)

Las personas que sobrellevan mejor la experiencia, son aquellas que sus sentimientos en transferencia les ayudan a una mejor comprensión de sí mismas.

Siguiendo con el asunto de si los MUD son terapéuticos, la autora plantea que ve tentador asentir, si es que el jugador está sometido a psicoterapia. Plantea además, que sí 
constituyen una gran ayuda de acuerdo con su experiencia clínica, ya que esos espacios virtuales, son intensamente evocadores y tienden a dinamizar un proceso de análisis.

La autora aborda los problemas de género, los juegos de roles sexuales, el asunto de la personalidad múltiple, la fidelidad, los niños en la red, los engaños y leyendas urbanas asociadas, la autora trata el asunto de la privacidad, y la implicación política de la virtualidad.

Esto último, asociado con las culturas que desarrollaron la informática, de vanguardia y contestaría, en esas fechas en manos de grandes corporaciones. La tensión entre Resistencia o Alienación es crucial en su análisis de los MUD, y los silencios que se imponen.

La censura, la vigilancia, el Gran Hermano orwelliano, a la altura de 1994 que se escribe el libro, ya se vislumbraba como posibilidad y realidad.

El panóptico, propuesto por J. Bentham, que es un mecanismo que posibilita a un guardia de prisión, una torreta, ver a todos los prisioneros sin ser visto, y los prisioneros se saben vigilados. El gentío sabe que la posibilidad de la vigilancia electrónica siempre está presente.

En suma el trabajo de la Dra. Turkle, que llevó muchos años de investigación bibliográfica y de campo, es una excelente mirada transdisciplinaria sobre el mundo de la informática y sus implicaciones, en la mujer y el hombre, niños y niñas de su país, su subjetividad individual y colectiva.

\section{De las pinturas prehistóricas a la era de la red de redes}

\subsection{Propósito}

Internet es con mucho uno de los mojones, que señalan una nueva frontera en el desarrollo científico tecnológico, en la eclosión de una nueva economía, de una nueva cultura, una novedosa cosmovisión, con implicaciones de naturaleza política, financiera, de alcance planetario.

En el ámbito de la comunicación, el autor del libro la Galaxia Internet (Castells, 2001) plantea, tres hitos fundamentales: las pinturas rupestres, la invención de la imprenta, y el 
surgimiento de Internet. Una minuciosa investigación lleva al autor a investigar sus orígenes que se dan en el Departamento de Defensa de los EE.UU., a finales de los años 50, con el proyecto ARPA, formado con la finalidad de movilizar recursos del mundo universitario, en momentos en que la Unión Soviética, había lanzado el primer satélite, el Sputnik. En plena Guerra Fría, eso fue un golpe a los Estados Unidos, en lo propagandístico, en lo científico, y en lo militar. Comenzaron las investigaciones con el proyecto ARPANET, en los albores de la computación on-line, y con la tecnología que después se utilizaría en las telecomunicaciones comerciales, de la conmutación por paquetes.

El problema es qué y para qué se trasiega, en la red. Concibiendo ésta como una estructura más amplia que Internet. Es decir que involucra, toda la infraestructura de comunicaciones, aéreas, terrestres, marítimas, espaciales, submarinas, reales y potenciales.

Cohetes que destruyen Bagdad o paracaídas con alimentos para paliar una hambruna. Transmisiones invasoras de la infame e insultante TV-Martí, o comunicados de Amnistía Internacional. Música enajenante, o música diversa, nostálgica, vital que refleja la cultura y los anhelos de los pueblos.

Es y será con arreglo al poder dominante. Sobre, en, y dentro del planeta existen redes, en la tríada-nodos, enlaces y contenidos de trasiego. Internet es la más visible y la más importante, pero no perdamos de vista las otras. (Coronado, 2000)

Se da una simbiosis entre los centros de investigación, universidades y el Pentágono, que dicho sea de paso es característico de los Estados Unidos.

El Gobierno propicia un determinado desarrollo tecnológico, con la colaboración de las universidades y algunas empresas. Cuando acaba con la aplicación militar, les pasa muchas veces gratis el desarrollo, a la empresa privada, e incluso subvenciona su introducción. De esa forma potencia la economía, con una inyección de patrimonio científico tecnológico de punta.

Una de las razones que apunta el autor para la caída del campo socialista, arrastrado por el derrumbe de la Unión Soviética, es la excesiva compartimentación y burocratización del desarrollo científico-técnico en el campo militar, lo cual trajo un rezago respecto a su enemigo los Estados Unidos. Pero a su vez, esa compartimentación, se traduce en una incapacidad histórica para trasladar las innovaciones oportunamente a las fuerzas productivas; lo cual 
genera que la industria y los servicios colapsen, al ser incapaces de producir con eficiencia y llenar las expectativas de consumo de la población.

Debemos apuntar otras razones, como el pleno empleo, la influencia mediática del "paraíso capitalista", el "Estado de Bienestar", que paradójicamente, le cobró la población al régimen, ávida de consumo, en medio del caos de la planificación central. Hoy, en medio del más salvaje Capitalismo de Estado, muchos añoran el antiguo régimen de bienestar, aún con sus colas y el autoritarismo.

Volviendo a Internet, el autor, la caracteriza como una posibilidad de los países del Tercer Mundo para acceder, en el ámbito de una estrategia de desarrollo más amplia, a la inserción de naciones, pueblos y regiones y bloques de países a la nueva economía basada en el uso intensivo de la información y el conocimiento, con términos de intercambio más justos y posturas de negociación más sólidas.

Pero no hay que llamarse a engaño, ya que en nuestros países el fenómeno de la exclusión es masivo, y hemos mencionado que la mitad de la humanidad vive bajo condiciones infrahumanas y no ha hecho nunca una llamada telefónica.

El autor aborda multidimensionalmente el fenómeno de Internet, la historia, la cultura, la economía, las comunidades virtuales y la sociedad red, la política de Internet, redes informáticas, sociedad civil y Estado, privacidad y libertad, el hipertexto, la distribución geográfica y otros temas. Para efectos de este ensayo nos concentraremos en la economía y el trabajo.

\subsection{La nueva economía de la red}

\subsubsection{El modelo neoliberal y sus implicaciones}

En la era de la globalización neoliberal, donde se impone la utopía de que el mercado es la única de las alternativas posibles, y no cabe una sociedad, ni un modo de producción alternativo a ella, Hinkelammert (1995) señala que no es fuente de asombro, que Internet, sea uno de los pilares de la etapa del capitalismo que vivimos.

Esta etapa la podemos caracterizar de la siguiente forma: 
- Un contexto político-económico caracterizado por la desregulación del libre flujo de capitales, cuya manifestación más evidente lo constituye el Acuerdo Multilateral de Inversiones, que deja al Estado-Nación, como mero guardián de los intereses de las grandes corporaciones (Hinkelammert, 1995)

-. Un Estado-Nación gendarme, encargado de sofocar las revueltas internas en los países centrales y periféricos, y de hacer incursiones de rapiña, para asegurar sus dominios geopolíticos y garantizar el acceso a los hidrocarburos, metales y otros recursos naturales (Hinkelammert, 1995)

- Una depredación inmisericorde de los recursos naturales, que pone en peligro los ecosistemas, al punto de que ya no hay marcha atrás, se ha iniciado un camino irreversible de cambio climático, y los Estados Unidos, se niegan a firmar el protocolo de Kioto, siendo ellos los responsables del $25 \%$ de las emisiones de $\mathrm{CO}_{2}$, acabándose a su vez las posibilidades de fijación de carbono, en los pulmones del planeta.

Un ejemplo es la Amazonia, es arrasada a razón de una porción del tamaño de Guatemala por año.

El desequilibrio aumenta exponencialmente la intensidad de los desastres hidrometereológicos, y sus estragos, que alcanzan y sufren con más intensidad, las poblaciones más vulnerables. (Boff, 1996)

- La organización del trabajo en la economía basada en el uso intensivo de la información y el conocimiento, ha cambiado sustantivamente. Las corporaciones compiten ferozmente entre sí, se fusionan en bloques cada vez más grandes y la concentración de capital aumenta. En su interior, las juntas directivas representan accionistas, que guiados por las Bolsas de Valores, son implacables con ellas. Estas a su vez son implacables, con sus ejecutivos. A quienes juzgan sin cortapisas por sus resultados individuales. $Y$ así en toda la escala ejecutiva, al punto que comienza a aparecer un "ejército ejecutivo de reserva".

Los empleados son sometidos a continuas evaluaciones del desempeño, se imponen la autoexplotación, trabajan largas y extenuantes jornadas. El empleo se precariza, los contratos son individuales y a plazo fijo. Se renuevan o no de acuerdo al desempeño individual. La competencia darwaniana, rompe con toda solidaridad colectiva (Bourdieu, 1999) 
- La jerarquía clásica de la estructura fordista, se convierte en estructuras sociales tipo red, heterogéneas entre ellas, homogéneas en su interior, la diferenciación es por conocimientos, aptitudes y habilidades. La movilidad social vía educación difícil, en los países centrales, en particular en EEUU, se dejó de invertir en educación superior y su acceso es para élites.

En los países periféricos, que se han logrado insertar a la nueva economía, en su diversidad, y fundamentalmente con América Latina, la educación secundaria pública ha sufrido un deterioro en los últimos 20 años, y el acceso a la educación superior, es también para privilegiados. Además la nueva economía, requiere una actualización constante y permanente para tener acceso a un empleo digno y una comprensión de fenómenos complejos.

\subsubsection{La economía de la red reticular}

Hay que apuntar que las transacciones financieras en la red, para el 2004, según las proyecciones que reseña Castells, alcanzarán los 9 billones de dólares, de los cuales, el 90\% se realizarán de empresa a empresa, lo que deriva en una profunda reestructuración de los negocios ya que la mayor parte de los flujos financieros se movilizan a través de Internet.

Independientemente de lo episódico del descalabro de las empresas.com en el 2000-2001, se ha producido una revolución en la organización de las empresas, sus estructuras, sus sistemas de planeamiento y programación de producción, operaciones, logística, distribución, y en ello incluimos políticas de inventarios, diseños en planta, modelajes de simulación avanzados basados en inteligencia artificial y caos, robótica y automatización industrial, tanto en producción como en servicios. Descentralizando proveedores y desarrollándolos en las diferentes regiones y países aprovechando economías de escala, y buscando reducir costos y maximizar beneficios aplicando con las últimas tecnologías de la administración, de la información, de la cibernética, la robótica y la ingeniería industrial, así como las propias del dominio de su área de negocios.

La empresa red, se caracteriza por una forma reticular de la organización, constituida alrededor de un proyecto de negocio y surge de la combinación de varias estrategias de 
trabajo en red. Además, implica la colaboración entre pequeñas y medianas empresas que unen sus recursos para acceder a un mercado más amplio ${ }^{8}$.

Apunta Castells, que buena parte del éxito de Cisko, caracterizado por la productividad y competitividad, se debe a su modelo organizacional. En el 2000 contaba con 150.000 usuarios registrados y accedían a ella 1.5 millones de veces al mes.

El usuario entra a la página de Cisko, especifica sus requerimientos y auxiliados por oficiales presupuestadores y configuradores en una red de representantes autorizados y certificados (clientes y socios), definen, ponen precios y una vez llegado a un acuerdo, los proveedores de Cisko, fabrican la mayor parte de los componentes y los envían directamente al cliente. EI servicio pos-venta es excelente. De esta forma el primer semestre del 2000 Cisko vendió 40 millones de dólares por día en línea, el $90 \%$ de los pedidos. El $60 \%$ de los pedidos están totalmente automatizados y no requieren intervención alguna por parte del personal de la empresa. Alrededor del $80 \%$ de servicios al consumidor final se solicitaron mediante la página de Cisko.

Dice Castells, "Cisko es un fabricante, pero está basado en una fábrica virtual y global sobre la que tiene la responsabilidad final en términos de $I+D$, ingeniería de prototipos, control de calidad y marca..." (Castells, 2001, p. 87).

Otras empresas que han adoptado con sus variantes, en el ramo de las telecomunicaciones en informática, son Dell, Nokia, Hewlett-Packard, IBM y Oracle.

Otras empresas transnacionales y pertenecientes a la economía tradicional, se han integrado a esta organización reticular, interesa destacar el acuerdo corporativo entre los gigantes de automotores General Motors, Ford Motors Company y Dailmer Chrysler, para constituir un sistema de intercambios en línea para proveedores de partes, que sería el e-business más grande del mundo.

${ }^{8}$ Cisko Systems, creada en el Valle del Silicón es el mayor productor de enrutadores o equipos electrónicos de eje troncal para Internet. Alcanzó en el 2000 un valor de mercado de 555 mil millones de dólares sobre el crak del .com y de las empresas de Nasdak. 
El caso de John Deere, la multinacional fabricante de maquinaria agrícola, que también está haciendo conexiones en red con sus clientes y usuarios, es otra evidencia de esta tendencia.

El caso que ilustra más vivamente, el surgimiento de una empresa-red, es Zara de la Coruña, España, país gallego, que comenzó, como una textilera y acabó convirtiéndose en una casa de moda que superó a Gap, y a la fecha del estudio tiene 1400 tiendas en 34 países, produce 12000 diseños por año y provee a sus tiendas, en todo el mundo dos veces por semana.

Por último se pueden reconocer, apunta, tres características del e-business :

- Escabilidad: La red puede integrar tantos o tan pocos componentes local y globalmente con arreglo a cada operación y a cada transacción. No existe para la red ninguna barrera que sea global o local, ya que puede moverse, expandirse, recogerse, por la naturaleza de su arquitectura, variable de la estrategia empresarial.

-. Interactividad: En tiempo real o el seleccionado entre proveedores, clientes, es un sistema multidireccional de información y toma de decisiones que resalta los canales verticales de información, sin perder de vista la transacción.

- Flexibilidad: Permite observar el control del proyecto empresarial a la vez que alcanza y diversifica la composición según los requerimientos de cada proyecto.

Quedan muchos temas como la política, la cultura, la privacidad, la brecha digital, la geografía internet del exhaustivo estudio de Castells.

Pero no olvidemos que es solo una, por más que sea lo más importante de las redes reales o potenciales, de las redes que la teoría de grafos nos permite conceptuar, como apuntábamos al inicio del capítulo. 


\section{Conclusiones}

Hemos hecho un análisis de tres temas y su importancia en la educación. Los Mapas Conceptuales son un instrumento herramienta que permite la representación y simulación de contenidos de aprendizaje, desde los más simples a los más complejos y se constituyen en un aporte innegable a la educación y al método de asimilación que encuentra allí una aplicación importante. El estudio analizado de la Dra. Turkle, permite implicar que la computadora tiene consecuencias fundamentales sobre mujeres y hombres, su conducta, sus modos de aprendizaje y su relación con este artefacto. Mención especial merece lo relacionado con las formas de aprender a programar y con las preferencias del usuario, tanto el que prefiere la opacidad, es decir una relación estricta con las herramientas de usuario final, sin preocuparse qué hay debajo de esa superficie, y el usuario que manipula los sistemas operativos y desarma su computador para indagar sobre sus componentes.

Las implicaciones de la interacción con los Dominios para Múltiples Usuarios, revelan importantes hallazgos psicológicos, relacionados con las ideas de Lacan y otros pensadores. Pero quizás lo más relevante es lo que se relaciona con los estilos de aprendizaje en el computador, la programación canónica sujeta a una concepción estructurada y de reglas estrictas y la programación de bricolaje, más libre y que permite el uso no solo del pensamiento analógico, sino lo lúdico y creativo. Ese último estilo domina hoy la enseñanza y aprendizaje de la programación.

La última parte del ensayo parte de la eclosión de Internet, se contextualiza el capitalismo neoliberal, el papel del Estado, la empresa y los trabajadores. Se analiza su desarrollo y sus consecuencias en la movilización de capitales mediante la red. Además se caracteriza la empresa reticular, modelo de la moderna sociedad de la información y el conocimiento. Las implicaciones de Internet para la educación se han reseñado abundantemente. Si hay un cambio en la organización de la empresa de la estructura fordista a la tipo red, homogéneos sus nodos, heterogéneos entre sí, hay implicaciones fundamentales para la educación, que implica renovarse varias veces en la vida laboral y el acceso a conocimientos cada vez más complejos. Pero también, la tendencia del Estado a invertir menos en educación y la aparición de un ejército laboral de reserva en todos los niveles.

Las consecuencias de Internet sobre la educación están ligadas a la economía organizada reticularmente. Podrán los estados invertir en equipos computacionales, en las escuelas y 
colegios públicos, pero sin embargo la llamada nueva economía, es profundamente excluyente. Aún más, esa inversión es ilusoria con las tendencias del neoliberalismo, lo que limita el aprendizaje de niños y jóvenes y el acceso a conocimientos más complejos.

El modelo de sociedad y de economía que caracteriza al Siglo XXI, está diseñado para la existencia de una masa de excluidos, y lo más dramático es que esta exclusión no hace diferencias entre países centrales y países periféricos. $Y$ recordemos que entre los excluidos, los hay de todas las extracciones sociales y en todos los sectores, aún los más educados y actualizados. De allí que podamos hablar del fenómeno del ejército ejecutivo de reserva. En suma, se han planteado tres miradas sobre temas relacionados con los medios digitales y la computación. 


\section{REFERENCIAS}

Boff, L. (1996). Ecología: Grito de la Tierra, grito de los pobres. $3^{\mathrm{a}}$ ed. Madrid: Editorial Trotta.

Bourdieu, P. (1999). La esencia del neoliberalismo. Venezuela Analítica. Recuperado el 2 julio del 2005, de http://www.analitica.com/bitblioteca/bourdieu/neoliberalismo.asp

Cañas, A. J. (et-al). Modelo para Construir y Compartir Modelos de Conocimiento Basados en Mapas Conceptuales. Recuperado el 2 de julio de 2005, de http://www.ihmc.us/users/acanas/Publications/RevistalnformaticaEducativa/Herramientas ConsConRIE.htm

Castells, M. (2001). La Galaxia Internet. Barcelona, España: Plaza y Janés Editores S.A.

Coronado, O. (2000). Crítica a la Teoría de Sistemas de Teoría como un complemento ilustrado con el diseño de un Sistema Nacional en Ambiente y Salud. Ponencia presentada en el Congreso Internacional de Telecomunicaciones e Informática. CITEL 2000. La Habana, Cuba. Memoria. Ediciones ISPJAE.2000. Modificada y presentada como artículo en: Ingeniería Enero / Diciembre 2001 - Volumen 11 - No 1-2. Editorial de la Universidad de Costa Rica. Costa Rica.

Hinkelammert, F. (1995). Cultura de la Esperanza y Sociedad sin Exclusión. San José: Departamento Ecuménico de Investigaciones (DEI).

Novak, J. (1998). Conocimiento y Aprendizaje. Los Mapas Conceptuales como Herramientas Facilitadoras para Escuelas y Empresas. Madrid: Ed. Cast. Alianza Editorial S.A.

Resnick, M. (1998). Thinking Like a Tree (and other for an Ecological Thinking). Recuperado el 2 de julio de 2005, de http://web.media.mit.edu/\%7Emres/papers/tree/

Turkle, S. (1997). La vida en la pantalla. La construcción de la Identidad en la era de Internet. Barcelona: Ediciones Paidós Ibérica S.A. 